\title{
Terminologia em contexto normativo relacionada com a entrada de estudantes na Universidade: uma pesquisa sobre a UNILA e a UNE
}

\author{
Terminology at legal framework context related to students' \\ entry to University: a research on UNILA and UNE
}

\author{
Terminología en contexto normativo relacionada con la \\ entrada de estudiantes a la Universidad: una investigación \\ sobre la UNILA y la UNE
}

\author{
Fidel Pascua Vílchez ${ }^{1}$ \\ Elisane Andressa Kaiser da Silva² \\ Isabel Mattos Schmidt ${ }^{3}$
}

\begin{abstract}
RESUMO: no presente artigo, é analisado, desde uma perspectiva terminológica, o léxico do marco normativo universitário (MNU) da Universidade Federal da Integração Latino-Americana (UNILA) e da Universidad Nacional del Este (UNE), relacionado com a entrada de estudantes nessas instituições. Com base em Wüster (1998), Gouadec (1990), Cabré (1993) e Krieger e Finatto (2004), a problemática é analisada desde dois pontos de vista: nacional- monolíngue e binacional-bilíngue. Foram estabelecidos dois corpora de documentos: um em português, composto por documentos do MNU da UNILA e outro em espanhol, por documentos da UNE; foram extraídos os termos e organizadas as fichas terminológicas; depois, foram estabelecidas as relações de equivalência entre conceitos de diferentes MNUs, para sua adequação da língua de partida à língua meta. Foram elaborados uma base de dados terminológica e um glossário bilíngue, destinados a auxiliar na recepção e produção de textos especializados relacionados com âmbito universitário a discentes, docentes, Técnicos Administrativos em Educação (TAEs), tradutores profissionais e intérpretes. Concluiu-se que: a) os estudantes, quando chegam às instituições, possuem um conhecimento prévio da terminologia acadêmica que não resulta suficiente para entender com precisão os documentos do $\mathrm{MNU}$; b) ambas universidades priviliegiam as línguas hegemônicas em seus MNUs, chamando a atenção o caso do Paraguai, país
\end{abstract}

${ }^{1}$ Doutor em Estudos da Linguagem pela Universidade Estadual de Londrina (UEL). Professor do quadro efetivo da Universidade Federal da Integração Latino-Americana (UNILA). fidel.vilchez@unila.edu.br.

2 Mestranda do Programa de Pós-Graduação em Literatura Comparada da Universidade Federal da Integração Latino-Americana (UNILA). elisane.silva@aluno.unila.edu.br

${ }^{3}$ Acadêmica do curso de Letras, Artes e Mediação Cultural (LAMC) da Universidade Federal da Integração Latino-Americana (UNILA). isabel.schmidt@aluno.unila.edu.br . 
oficialmente bilíngue espanhol-guarani, pois o MNU da UNE está apenas escrito em espanhol; c) existe uma grande quantidade de siglas nos documentos do MNU que nem sempre vêm acompanhadas de seu significado explícito, dificultando a compreensão do leitor.

PALAVRAS-CHAVE: Terminologia. Terminografia. Marco normativo universitário.

ABSTRACT: in present paper, it is analysed, according to a terminological perspective, the vocabulary included at the University legal framework (ULF) of Universidade Federal da Integração Latino-America (UNILA) and Universidad Nacional del Este (UNE), related to students' entry in these two institutions. Being based on Wüster (1998), Gouadec (1990), Cabré (1993) and Krieger e Finatto (2004), we analyse the matter through two points of view: a) national and monolinguistic; b) binational and bilinguistic. In the first case, two corpora of documents are obtained: one in Portuguese, formed by documents from ULF of UNILA and another one in Spanish, formed by documents from UNE; afterwards, terms are extracted and organized in terminological index cards; in the second case, are settled the equivalence relations between concepts from different ULFs, in order to adapt from source language into target language. As resulting objects from the research, were elaborated one terminological database and one bilingual glossary, both intended for helping students, teachers, administrative secretarial assistants (ASAs), professional translators and interpreters on reception and production of specialized texts in the context of University. We conclude that: a) students, when entering the University, have a preexisting knowledge of Higher Education terminology that isn't enough to properly understand ULF documents; b) both universities give priority hegemonic languages in their ULFs, drawing particularly attention to Paraguay situation, an officially bilingual Spanish-Guarani country, but UNE's ULF is entirely in Spanish; c) ULF documents contains a lot of acronyms, not always supported by their explicit meaning, rendering the documents rather less easily comprehensible.

KEYWORDS: Terminology. Terminography. University legal framework.

RESUMEN: en el presente artículo, analizamos, desde una perspectiva terminológica, el léxico del marco normativo universitario (MNU) de la Universidad Federal de la Integración Latinoamericana (UNILA) y de la Universidad Nacional del Este (UNE), relacionado con la entrada de estudiantes a estas instituciones. Con base en Wüster (1998), Gouadec (1990), Cabré (1993) y Kriger e Finatto (2004), la problemática se analiza desde dos puntos de vista: nacional-monolingüe y binacional-bilingüe. Fueron establecidos dos corpora de documentos: uno en portugués, compuesto por los documentos del MNU de la UNILA y otro en español, por los documentos de la UNE; de los cuales, se extrajeron los términos y se organizaron en fichas terminológicas; después, se establecieron las relaciones de equivalencia entre conceptos de diferentes MNUs, para su adecuación de la lengua de partida a la lengua meta. Fueron elaborados una base de datos terminológica y un glosario bilingüe, dirigidos a auxiliar en la recepción y producción de textos especializados relacionados con el ámbito universitario a discentes, docentes, técnicos administrativos en educación (TAEs), traductores profesionales e intérpretes. Concluimos que: a) los estudiantes, cuando llegan a las instituciones, tienen un conocimiento previo de la terminología académica 
que no resulta suficiente para entender con precisión los documentos del MNU; b) ambas universidades dan privilegio a las lenguas hegemónicas en sus MNUs, llamando la atención el caso de Paraguay, país oficialmente bilingüe en español y guaraní, pues el MNU de la UNE está escrito apenas en español; c) existe una gran cantidad de siglas en los documentos del MNU que no siempre vienen acompañadas de su significado explícito, dificultando la comprensión del lector.

Palabras clave: Terminología. Terminografía. Marco normativo universitario.

\section{Introdução}

Este artigo, fruto de um projeto de Iniciação Científica, analisa o léxico do marco normativo universitário (doravante MNU) da Universidade Federal da Integração Latino-Americana (UNILA), sediada em Foz do Iguaçu - PR e da Universidad Nacional del Este (UNE), localizada em Ciudad del Este, Paraguai, bem como a problemática da terminologia acadêmica bilíngue portuguêsespanhol. Descreve também a elaboração de um banco de dados e um glossário bilíngue de termos acadêmicos, com o propósito de auxiliar discentes, docentes, técnicos administrativos e demais interessados no uso correto dos conceitos, terminologias e suas equivalências adequadas em ambas às línguas elencadas.

A UNILA recebe estudantes da maioria de países da América Latina. No total, ingressaram em 2017.1 1.121 estudantes oriundos dos países hispânicos da América do Sul, América Central, Caribe e América do Norte, representando - $31,36 \%$ dos ingressantes totais. Os países que mais tiveram alunos matriculados foram Paraguai, Colômbia, Peru, Argentina e Chile; portanto, os termos linguísticos usados pelas suas comunidades docente e discente variam em função da origem dos indivíduos; no entanto, o MNU da instituição está escrito somente em português.

Assim como qualquer outra instituiçao de educação superior, a nossa instituição também está regida por um conjunto de normas expostas em uma série de documentos, organizados de maneira hierárquica, que constituem seu MNU e que contribuem para uma melhor organização e funcionamento da 
Universidade, mas para que isso aconteça é preciso que estas normas estejam bem explícitas para serem interpretadas e respeitadas por todos.

Entretanto, foi constatado que os acadêmicos estrangeiros, ao solicitarem informações nos centros administrativos da Universidade, como Secretaria Acadêmica, PRAE e outros, encontram dificuldades tanto para obter informações ou solucionar problemas em relação aos documentos, uma vez que são atendidos somente por técnicos administrativos em educação (TAEs) de nacionalidade brasileira, que nem sempre estão aptos para realizar a tradução dos documentos do português para o espanhol ou viceversa, quanto para compreender termos específicos e suas equivalências.

Quanto à metodologia aplicada para o desenvolvimento da pesquisa, inicialmente foram selecionados os documentos e posteriormente foi feita a extração dos termos que constituíram as unidades terminológicas da base de dados. Para isso, foram pesquisados os MNUs da UNILA e da UNE.

O léxico acadêmico é usado pelos membros da comunidade acadêmica, no cotidiano, como parte do acervo comum da língua; no entanto, esse mesmo léxico, uma vez incluído no MNU (Estatuto, Regimento Geral, PDI, Instruções Normativas, Resoluções, Editais, etc.), usado em comunicações especializadas (trámites em órgãos da instituição, secretarias etc) por usuários específicos (discentes, docentes, TAEs, cargos administrativos etc) constitui então a terminologia de uma área específica. De acordo com Cabré (1993, p. 37): "Para os especialistas, a terminología é o reflexo formal da organização conceptual de uma especialidade, de um meio inevitável de expressão e comunicação profissional".

Considerado o léxico acadêmico como uma terminologia específica, é preciso, então, definir o que é um termo nesse dado contexto.

Constamos que ao longo do tempo foram várias as definições de "termo" oferecidas pelos linguistas voltados à ciência terminológica (WÜSTER, 1998), (REY, 1995), (RONDEAU, 1983), (GOUADEC, 1990). A definição oferecida por 
Gouadec refere-se a conceitos, objetos e processos, justamente as mesmas noções incluídas nos documentos do MNU, alvo da pesquisa:

Um termo é uma unidade linguística que designa um conceito, um objeto ou um processo. O termo é a unidade de designação de elementos do universo percebido ou concebido. Ele raramente se confunde com a palavra ortográfica (GOUADEC, 1990, p. 3).

Portanto, de acordo com o autor, termo e palavra se diferenciam, pois o primeiro é um conceito unívoco, é compartilhado por um grupo específico, para uma comunicação especializada; já a palavra tem significado e uso variável e pertence ao acervo comum da língua.

\section{O bilinguismo na UNILA}

A pesquisa realizada está relacionada com o contexto de bilinguismo em que as atividades científico-acadêmicas da UNILA são desenvolvidas na instituição.

Com efeito, A UNILA, através do Artigo $2^{\circ}$ do seu Estatuto, promove sua vocação latino-americana e apresenta, como uma das suas missões, compartilhar, gerir, transmitir, difundir e aplicar os conhecimentos produzidos, buscando soluções para os problemas da América Latina:

A UNILA, universidade federal pública brasileira, tem vocação latinoamericana, compromisso com a sociedade democrática, multicultural e cidadã e fundamenta sua atuação no pluralismo de ideias, no respeito pela diferença e na solidariedade, visando a formação de acadêmicos, pesquisadores e profissionais para o desenvolvimento e a integração regional (UNILA, 2012).

Portanto, para que isso ocorra, queda-se lógico o uso de mais de uma língua além do português. Sendo no caso o espanhol a língua de uso comum da maioria dos países integrantes da America Latina, ficou esta como língua adicional de uso na instituição, como um dos princípios que a regem: "A UNILA 
rege-se pelos seguintes princípios: [...] a educação bilíngüe: português e espanhol." (UNILA, 2013).

Por sua vez, o Plano de Desenvolvimento Institucional (PDI) 2013 - 2017 da UNILA, no item 3.2, que trata sobre princípios filosóficos e metodológicos institucionais, diz que: "São princípios da universidade a interdisciplinaridade, a interculturalidade, o bilinguismo e o multilinguismo, a integração solidária e a gestão democrática." (UNILA, 2013, p. 15)

Mais adiante, no item específico sobre bilinguismo e multilinguismo, no de número 3.2.3 consta a seguinte citação:

A UNILA destaca, dentre as condições culturais essenciais para a realização do projeto de integração latino-americana e caribenha, o princípio de bilinguismo (português e espanhol), o qual se articula nos diversos âmbitos administrativos, científicos e pedagógicos da universidade (UNILA, 2013, p. 17).

Foi constatado que, nos âmbitos científico e pedagógico, esta premissa é verdadeira, uma vez que as classes são ministradas em ambos os idiomas, bem como são desenvolvidas pesquisas e teses que envolvem o português e 0 espanhol ou mesmo outros idiomas como o guarani, falado no Paraguai. Também são realizadas leituras de textos e livros em espanhol e em português. Inclusive, muitos dos docentes da instituição, têm como língua materna o espanhol.

Reforçamos esta ideia do bilinguismo com o exemplo do Ciclo Comum de Estudos (CCE), que possui a disciplina de Português para os hispano falantes e a disciplina de Espanhol para os lusófonos. Sendo assim, todos os discentes, independente da carreira elegida, deverão fazer no mínimo 20 créditos de uma de estas disciplinas de língua. Além disso, há projetos de extensão que também contribuem para a difusão das línguas em questão que abrem a oportunidade para a comunidade e técnicos-administrativos para aprender o espanhol e outros idiomas, como, por exemplo, o guarani, quéchua, alemão, valorizando não só o bilinguismo como também o multilinguismo. 
Mas, quanto à questão administrativa, o mesmo não ocorre, pois os documentos disponibilizados para consulta, estatutos, regimentos, editais e 0 próprio PDI estão todos em português e o pessoal que compõe as TAEs são todos de origem brasileira, monolíngues em português, sem fluência em espanhol. Devemos acrescentar que os procesos seletivos não exigem proficiência em espanhol

Este fato nos levou a procurar situações que causam conflitos lingüísticos no momento em que hispano falantes buscam na Secretaria Acadêmica informações ou realizar procedimentos necessários para efetuar matrícula, validar documentos, receber auxílios e outras demais funções realizadas junto a esses órgãos administrativos.

Na graduação, há duas formas de seleção para entrar na UNILA, sendo uma para os estudantes brasileiros e outra para os estudantes dos demais países latino-americanos e caribenhos.

No caso dos estudantes brasileiros, a seleção é feita com base na nota do Exame Nacional do Ensino Médio (ENEM), e também podem ingressar na Universidade por meio do Sistema de Seleção Unificada (SISU).

Alguns cursos como, por exemplo, Música e Arquitetura utilizam um método próprio, com provas de habilidades específicas, enquanto os estudantes dos outros países são selecionados em seu próprio país de origem pelo respectivo Ministério da Educação ou outro órgão governamental, mas para que os discentes consigam ingressar na Universidade é preciso que apresentem variados documentos pessoais, como, por exemplo Certidão de nascimento, Comprovante de residência, Histórico escolar e vários outros.

Foi justamente nesse processo de matrícula que foi identificada a dificuldade de comunicação entre os estudantes hispanofalantes com técnicos administrativos ou vice-versa, como também a compreensão dos termos que constam nos editais, uma vez que só estão apresentados em português.

Em conversa mantida com duas TAEs, responsáveis pelo atendimento direto dos discentes hispano falantes, foram levantados questionamentos sobre 
palavras que causavam maior conflito. Ambas lembraram rapidamente do termo "hipossuficiência", pois, atualmente, os estudantes não brasileiros estão em período de renovação do Registro Nacional de Estrangeiros (RNE) - visto de permanência, pelo qual devem pagar uma taxa obrigatória de que os estudantes se tornam isentos ante apresentação deste documento na Polícia Federal.

As funcionárias relataram que dificilmente os estudantes chegam pedindo na Pró-Reitoria de Assuntos Estudantis (PRAE) da Universidade pelo documento de "hipossuficiência", muitas vezes confundem com "atestado de residência", "auxílio subsídio" ou pedem por "aquele documento"; entretanto, as funcionárias não souberam explicar se existe um termo equivalente em espanhol para facilitar a compreensão desta palavra para os hispano falantes.

Partiu-se da hipótese de que devem existir variações terminológicas que representem este conceito, de acordo com o país da América Latina. Inclusive, de que a variação pode existir entre instituições do mesmo país.

\section{Objetivos propostos}

Em virtude dessa problemática, relacionada às dificuldades de interpretação exata de alguns termos presentes nos documentos da Universidade e a dificuldade de comunicação entre discentes e técnicos administrativos e vice-versa, traçamos, como objetivos principais deste estudo, a criação de uma base de dados terminológica e de um glossário bilíngue português - espanhol/ espanhol - português de termos acadêmicos relacionados com a entrada de alunos na instituição.

Além desses dois objetivos principais, foram propostos os seguintes objetivos específicos:

a) Contribuir para resolver os problemas de interpretação dos termos acadêmicos da UNILA e da UNE, definindo, sob uma perspectiva terminológica, os conceitos acadêmicos subjacentes nos 
documentos que os compõem, por meio de um enfoque bilíngue espanhol-português/português-espanhol.

b) Auxiliar tradutores profissionais, intérpretes, pessoal docente, discente e administrativo de ambas universidades, mediante a criação de uma ferramenta de consulta útil que possa servir de referência no que se refere à terminologia do mundo acadêmico universitário.

c) Facilitar a comunicação entre as instituições de Ensino Superior do Brasil e do Paraguai, para os trâmites administrativos em relação à convalidação e revalidação de diplomas, equivalência de disciplinas, cursos, programas, etc.

d) Diminuir os possíveis prejuizos causados a alunos, professores, pesquisadores e TAEs que estejam exercendo ou queiram exercer alguma atividade acadêmica nas instituições de Ensino Superior destes dois países, por causa da interpretação errada de termos acadêmicos na tradução dos seus documentos.

e) Contribuir com o projeto de integração latino-americana da UNILA.

\section{Metodologia aplicada}

Quanto à metodologia aplicada, em primeiro lugar, delimitamos o objeto de estudo do projeto; ou seja, os termos acadêmicos explícitos nos MNUs da UNILA e da UNE relacionados com a entrada de alunos em ambas instituições; em seguida, foi feita a recensão de documentos necessários, principalmente procedentes da Pró-Reitoria de Graduação (PROGRAD) e da Pró-Reitoria de Relações Internacionais (PROINT), de livre acesso no site da Universidade; em terceiro lugar, procedeu-se à extração dos termos, representativos de conceitos relacionados com pessoas-documentos e processos.

Sendo assim, os termos selecionados foram aqueles relacionados a: 
a) Entrada de estudantes na Universidade, à conclusão de curso ou documentos atrelados ao ensino e aprendizagem, como, por exemplo: histórico escolar, certificado de conclusão de curso etc.

b) Processos acadêmicos que estabelecem uma relação entre os discentes e a instituição de Ensino Superior, como, por exemplo, reingresso, reopção de curso, etc.

c) Algum nível de estudos universitário, como, por exemplo: bacharelado, licenciatura etc.

Uma vez feita a extração dos termos, organizamos as fichas terminológicas, uma parte essencial para a elaboração do banco de dados.

\title{
0 banco de dados
}

A elaboração das fichas terminológicas é uma parte fundamental para a elaboração da base de dados e da proposta de glossário, pois nelas estão presentes todas as informações referentes ao termos selecionados. De acordo com Krieger e Finatto (2004, p. 136):

\begin{abstract}
A ficha terminológica [...] pode ser definida como um registro completo e organizado de informações referentes a um dado termo. Nela, constam informações indispensáveis, tais como a fonte textual de coleta de um termo, segmentos de texto onde esse termo ocorre, seus contextos de uso, informações sobre variantes denominativas, sinônimos, construções recorrentes que o acompanham. A ficha também reúne informações operacionais ao trabalho, tais como o nome do responsável pela coleta, datas de registro e revisão, etc.
\end{abstract}

Figura 1 - Modelo de ficha terminológica em Micrososoft Accessvista: formulário. 


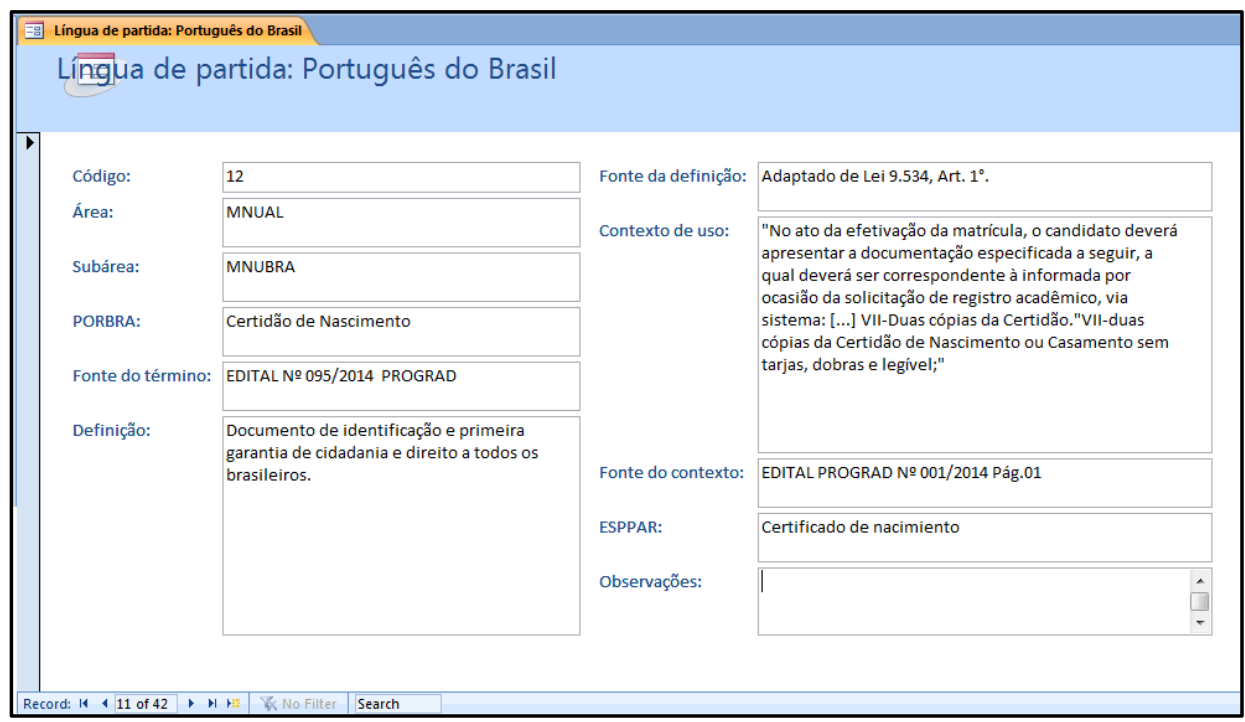

Fonte: Os próprios autores

Para o registro das informações dos principais termos selecionados, foi utilizado o programa Access, incluído no pacote Office, da companhia multinacional Microsoft, no qual foram organizadas em diversos campos e preenchidas com as informações completas dos términos (Figura 1).

\section{Os campos da ficha terminológica}

Especificamos, a seguir, os campos que compõem as fichas do banco de dados terminológico:

Código: numeração do termo correspondente, representada com três dígitos, partindo do 001 e assim, sucessivamente, até o último dos termos, em ambas as tabelas da base de dados: Língua de partida-Português e Lengua de entrada-Español.

Área temática: sempre preenchido com a sigla MNUAL (Marco normativo universitário da América Latina), quando a língua de entrada (LE) é o português, e, por sua vez, com MLUAL (Marco legal universitario de América Latina), quando a LE é o espanhol.

Subárea temática: sempre preenchido com a sigla MNUBRA (Marco normativo universitário brasileiro), quando a LE é o português, e, por sua vez, com a sigla MLUPAR (Marco legal universitario de Paraguay), quando a LE é o espanhol. 
Termo em língua de partida: quando a LE é o português brasileiro, este campo aparece preenchido com o termo nessa língua, precedido da sigla PORBRA, com a mesma forma que aparece também no glossário terminológico bilíngue como verbete; por sua vez, quando o espanhol é a $L E$, o termo aparece precedido da sigla ESPPAR.

Fonte do termo: indicamos a fonte documentária da qual o termo na LE foi selecionado (Lei, Estatuto, Regimento, etc.).

Definição: neste campo aparece a definição do termo na LE correspondente, a qual servirá também como definição na proposta de glossário bilíngue.

Fonte da definição: este campo aparece preenchido com a menção ao tipo de documento normativo do Brasil ou do Paraguai e, se for o caso, o artigo, do qual foi extraída a definição do termo na LE.

Contexto: contexto situacional em que o termo da LE relacionado aparece. As informações fornecidas para este campo ajudarão a entender melhor o sentido da definição do termo, como complemento dela.

Fonte do contexto: neste campo fazemos menção à fonte documentária do contexto em que o termo da LE aparece (Lei, Parecer, Estatuto, etc.).

Termo em língua de chegada: quando a LE é o português brasileiro, este campo aparece introduzido pela sigla ESPPAR e, na sequência, o termo equivalente em língua espanhola; por sua vez, quando a LE é o espanhol, o termo equivalente está introduzido pela sigla PORBRA.

Observações: este campo está reservado para as informações adicionais relevantes que possam ajudar na compreensão completa do conceito representado pelo termo de entrada. Este campo nem sempre aparece preenchido.

\section{O glossário}

O glossário fruto da pesquisa tem por objetivo ser uma ferramenta de consulta útil de caráter bilíngue, tanto para discentes de nacionalidade 
brasileira e paraguaia, quanto para docentes e técnicos administrativos da Universidade que estão em constante contato com o léxico acadêmico universitário em suas relações acadêmicas ou de trabalho.

A criação dessa ferramenta de consulta tem o intuito de auxiliar o consulente a obter uma definição clara dos termos de uso acadêmico e a conhecer os seus equivalentes, tanto em português quanto em espanhol, sobretudo que também contribua para diminuir os problemas de interpretação de tais termos.

De acordo com González-Jover (2006, p. 171):

Glossário: faz referência ao conjunto de palavras relacionadas com uma disciplina ou campo profissional, científico ou acadêmico, de sentido pouco claro ou difícil de entender para quem não pertence a ele, ordenadas alfabeticamente e que pode conter (embora não necessariamente) uma definição ou um comentário breve sobre essas unidades; ainda, costuma estar vinculado a um texto mais amplo; por exemplo: glossário de termos informáticos, glossário de economia etc.

As informações coletadas e organizadas nas fichas terminológicas serviram para a elaboração do glossário. Apresentam-se, de maneira sucinta, a seguir, suas funções, possíveis consulentes e estrutura:

\section{Funções do glossário}

Auxiliar na decodificação em língua materna, seja espanhol do Paraguai ou português brasileiro, para auxiliar discentes, docentes, TAEs, etc., quando estejam na situação de não entenderem determinado termo registrado em um dos documentos do $\mathrm{MNU}$, ou qualquer outro documento surgido das instituições de Ensino Superior do seu próprio país com as quais tenham relação.

Auxiliar na decodificação em língua estrangeira, espanhol para os consulentes brasileiros e português para os consulentes hispanofalantes paraguaios, ao se depararem com textos na língua meta que incluam léxico acadêmico, principalmente aqueles pertencentes ao $\mathrm{MNU}$, como no caso anterior, em situações de intercâmbio acadêmico, programas de colaboração 
entre Universidades, revalidação de diplomas, participação em eventos, simpósios, etc.

Auxiliar na codificação em língua materna, principalmente dirigido ao pessoal envolvido nos órgãos de deliberação e governo das instituições de Ensino Superior, nos casos em que possam surgir dúvidas quanto à denominação de pessoas, objetos e/ ou processos relacionados com a parte acadêmica da Universidade, assim como também àquelas pessoas que fazem parte do governo de centros e departamentos universitários, pelo mesmo motivo.

Auxiliar na codificação em língua estrangeira: acreditamos que o glossário pode ser de alguma utilidade para TAEs, pessoal do Serviço de Relações Internacionais das Universidades brasileiras e paraguaias, na hora de facilitar a membros da comunidade acadêmica falantes da língua meta (espanhol para os brasileiros e português para os hispanos) os equivalentes dos termos da sua língua materna, nos contextos de preenchimento de formulários, convaliação de disciplinas, revalidação de títulos, etc.

\section{Possíveis consulentes}

a) Legisladores em matéria de Ensino Superior do Brasil e do Paraguai.

b) Tradutores profissionais do Brasil e do Paraguai.

c) Membros de instituições públicas e privadas relacionadas com o ensino, a pesquisa e a extensão universitária no Brasil e no Paraguai.

d) Membros dos órgãos de governo das instituições de Ensino Superior brasileiras e paraguaias.

e) Membros dos órgãos de direção dos Centros e Departamentos das instituições de Ensino Superior brasileiras e paraguaias.

f) Pessoal do Serviço de Relações Internacionais das Universidades do Brasil e do Paraguai.

g) Serviços jurídicos das Universidades do Brasil e do Paraguai. 
h) Funcionários dos órgãos de apoio das Universidades do Brasil e do Paraguai.

i) Professores e pesquisadores das Universidades do Brasil e do Paraguai.

j) Estudantes das Universidades do Brasil e do Paraguai.

k) TAEs das Universidades do Brasil e do Paraguai.

\section{Estrutura do glossário}

A estrutura do glossário está organizada em função do seu propósito e das características e necessidades dos possíveis usuários expostas anteriormente.

A obra apresenta uma estrutura bilíngue bifocal: língua de partida A para língua de chegada $B$ (no nosso caso: português - espanhol) e língua de partida B para língua de chegada A (no caso: espanhol - português). No entanto, cada uma dessas duas partes terá entidade por si mesma, como unidades monofocais, organizadas em função de uma língua de partida $A$ para uma língua de chegada $B$, cada uma com sua superestrutura, macroestrutura e microestrutura.

Em consequência, a superestrutura está composta de três partes:

a) Introdução: texto introdutório que serve de apresentação do mesmo ao usuário e dá as recomendações de uso, tanto em português quanto em espanhol.

b) Superestrutura monofocal 1: composta pelas macroestrutura e microestrutura na direção português - espanhol.

c) Superestrutura monofocal 2: composta pelas macroestrutura e microestrutura na direção espanhol - português.

Por sua vez, cada superestrutura monofocal estará composta por macroestrutura e microestrutura. 
A macroestrutura está composta pelo termo-entrada em português ou espanhol, segundo o caso, ordenada de maneira alfabética.

Microestrutura do glossário: a microestrutura do glossário apresenta:

Termo-entrada: a unidade terminológica UT em forma de lema, em português ou espanhol, dependendo da direção do glossário, organizado em ordem alfabética e grafado em negrito. Por exemplo: abandono de curso, admissão, etc., em português; por sua vez, admisión, alumno libre, alumno regular, etc., em espanhol.

Informação gramatical sobre o lema: esta informação refere-se ao gênero gramatical do substantivo que constitui o termo-entrada, pois todos os lemas do glossário são substantivos ou equivalentes. Consideramos relevante oferecer esta informação, pois pode ser útil na hora da recepção ou produção de textos. Aparece grafada em itálico. Por exemplo: abandono de curso $m$.

Definição: a definição terminológica está redigida na mesma língua do termo-entrada; ou seja, no dicionário com direção português - español, a definição está em português e, no dicionário na direção espanhol - portugués, a definição está em espanhol.

Contexto: o contexto corresponde a um extrato de um documento pertencente ao MNU brasileiro ou paraguaio, segundo a direção do glossário; aparece na mesma língua do termo-entrada, entre aspas para marcar que se trata de uma citação textual e vem precedido de um símbolo (fonte Wingdings 11), representando uma mão escrevente, para facilitar na leitura a localização rápida da citação. Dentro do contexto, sempre vem um exemplo de uso do termo-entrada, o qual vai entre os signos < (menor que) e $>$ (maior que), igualmente para facilitar sua localização no texto. A seguir, a fonte documentária da citação textual, precedida de um símbolo 圈 (fonte Wingdings 11), em forma, justamente, de documento, para facilitar sua localização no texto.

Termo equivalente: aparece apresentado também em forma de lema, em espanhol, quando o glossário tem língua de partida PORBRAS e, por sua vez, 
em português quando o glossário tem língua de partida ESPAR. Aparece precedido da sigla ESPAR quando se trate do equivalente em espanhol do Paraguai e vice-versa: precedido da sigla PORBRA quando se trata do equivalente em português brasileiro. Ainda, ele está grafado em negrito e em itálico, para salientar, por um lado, sua equivalência em relação ao termoentrada e, por outro, que se trata de uma língua diferente.

Informação gramatical sobre o termo equivalente: da mesma forma que acontecia com o termo-entrada, o termo equivalente também possui sua informação gramatical, pelo mesmo motivo de facilitar a tradução. Refere-se apenas ao gênero gramatical, pois todos são substantivos ou equivalentes a substantivos, e está grafado em itálico.

Observações: esta parte do glossário não aparece preenchida em todos os verbetes. Apenas nos casos em que a informação fornecida através da definição e o contexto não é suficientemente esclarecedora, ou precisa ser acrescentada alguma informação adicional relevante para possibilitar um sentido completo. Também nos casos em que exista alguma diferença específica, matiz ou detalhe, quanto à equivalência entre o termo-entrada e o termo proposto como equivalente. Inclusive, não tem uma estrutura idêntica nas duas línguas de partida. Formalmente, o corpo do texto das obrservações vem introduzido por um símbolo Fonte MS Mincho 11), em forma de dedo indicador apontado, para facilitar sua rápida localização fora do corpo principal do verbete.

Oferecemos um exemplo de verbete com língua de partida português brasileiro, assinalando através dos números cada uma das suas partes (Quadro 1):

Quadro 1 - Exemplo de verbete no glossário: Processo Seletivo Nacional de alunos

Processo Seletivo Nacional de alunos $m$ Processo de seleção de alunos, conforme critérios estabelecidos pela Universidade, para o preenchimento das vagas oferecidas nos cursos de Graduação e destinadas a candidatos brasileiros 
participantes do ENEM. "Os resultados do <Processo Seletivo Nacional de alunos> para o qual se abrem inscrições neste Edital são válidos para o ingresso no primeiro semestre do ano letivo de 2015." 祭EDITAL PROGRAD No 095/2014. ESPPAR Proceso Selectivo Nacional de alumnos $m$

- Paráfrase. No Paraguai, não existe uma prova nacional de acesso à Universidade; no entanto, algumas universidades mantêm, como requisito, em seus processos seletivos, superar algum tipo de prova como instrumento de avaliação dos conhecimentos dos candidatos.

Fonte: Os próprios autores.

\section{Conclusão}

Tendo em vista as dificuldades presenciadas diariamente na Universidade, devido às complicações para compreender certos termos acadêmicos, acreditamos que o glossário bilíngue de termos acadêmicos será uma ferramenta de consulta para facilitar a compreensão dos mesmos.

Levando em conta que nos documentos da UNILA concernentes ao ingresso de alunos há um grande número de siglas, como, por exemplo: CPF, RG, ENEM, MEC, entre outras, foi necessário realizar uma pesquisa mais ampla, pois, além de fazer buscas para encontrar a definição para cada uma destas siglas, também foi preciso explicar seus significados, que geralmente se referiam a nome de documentos, lugares ou instituições; por isso, se fez necessário abrir novos campos para cada sigla encontrada e preenchê-los com seus significados, para que, dessa forma, quem vier a utilizar-se do glossário, possa ter informações mais completas.

Este glossário será útil não só para os hispanofalantes que desejam vir estudar ou já estudam na universidade, mas também será uma ferramenta de pesquisa para nós, lusofalantes, que muitas vezes temos dificuldades de compreendermos termos acadêmicos ou siglas nos documentos da nossa própria Universidade. 
Constatamos também que em ambas universidades são preservadas línguas hegemônicas; no caso da UNILA, o português; e, na UNE, o espanhol. Porém, sabe-se que, na primeira, o espanhol não se faz presente nos documentos, apesar de ser "latino-americana" e o mesmo ocorre com a UNE que não possui documentação em guarani, apesar desta ser uma língua oficial do Paraguai:

El Paraguay es un país pluricultural y bilingüe. Son idiomas oficiales el castellano y el guaraní. La ley establecerá las modalidades de utilización de uno y otro. Las lenguas indígenas, así como las de otras minorías, forman parte del patrimonio cultural de la Nación (REPÚBLICA DEL PARAGUAY, 1992).

De fato, a Constituição de 1992 do Paraguai também está escrita em guarani:

Paraguái ha'e tetã hembikuaa arandu heta ha iñe'ẽ mokõiva. Estado ñe'ẽ tee ha'e castellano ha guarani. Léipe ha'íva'erã mba'éichapa ojepo rúta mokõivéva. Mayma ypykue ñemoñare ñe'ẽ ha opaite imbovyvéva ñe'ẽ ha'e tetã rembikuaa arandu avei (REPÚBLICA DEL PARAGUAY, 2017).

É imprescindível ressaltar que, tanto na pesquisa realizada nos documentos da UNILA quanto da UNE, não foi encontrado nenhum termo na língua guarani, e, menos ainda, em alguma outra língua originária da América Latina. Isso é uma questão que consideramos importante que seja repensada, pois ambas as universidades recebem estudantes que, muitas vezes, têm como língua materna o guarani, quechua, crioulo, entre outras, sendo que, inserir essas línguas nos documentos, também seria uma forma de preservá-las.

Foi comprovado que o aluno tem um pré-conhecimento do léxico incluído no MNU ao ler os documentos, porém isso nem sempre o ajuda na decodificação do texto. Por este motivo, o glossário poderá servir como auxílio ao consulente, pois ali, num só texto, achará os termos que busca para entender os editais e documentação necessária para entrar na universidade. 
Estamos cientes de que o glossário está em sua primeira versão, sujeito, portanto, ao aprimoramento, com base em novas pesquisas ou na sugestão de inclusão de novos termos ou de definições mais precisas.

Agradecemos à UNILA e ao PIBIC pela bolsa disponibilizada.

\section{Referências}

CABRÉ, María Teresa. La terminología. Barcelona: Empúries, 1993.

GÓMEZ GONZÁLEZ-JOVER, Adelina. Terminografía, lenguajes profesionales y mediación interlingüística. Alicante: Universidad de Alicante, 2006.

GOUADEC, Daniel. Terminologie: constitution des données. Paris: Afnor, 1990.

KRIEGER, Maria da Graça; FINATTO, Maria José Bocorny. Introdução à terminologia. São Paulo: Contexto, 2004.

REPÚBLICA DEL PARAGUAY. Constitución Nacional de 1992. Tribunal Superior de Justicia Electoral. Asunción, 1992. Disponible en:

<http://tsje.gov.py/constituciones.php>. Acesso em: 12 maio 2017.

REPÚBLICA DEL PARAGUAY. Nande Léi Guasu. Disponível em:

<https://servicios.sfp.gov.py/sfp/?node=download,1745,uc7564d47e,sor > . Acesso em: 12 maio 2017.

REY, Alain. Essays on terminology. Tradução de Juan C. Sager. Philadelphia: John Benjamins Publishing Company, 1995.

RONDEAU, Guy. Introduction à la terminologie. Quebec: Gaëtan Morin, 1983.

UNILA - UNIVERSIDADE FEDERAL DA INTEGRAÇÃO LATINO-AMERICANA. Estatuto. Foz do Iguaçu, 2012. Disponível em:

<http://www.unila.edu.br/sites/default/files/files/ESTATUTO\%20UNILA\%20de \%2026\%20DE\%2009(2)(1)(1).pdf>. Acesso em: 9 maio 2017.

UNILA - UNIVERSIDADE FEDERAL DA INTEGRAÇÃO LATINO-AMERICANA. Plano de desenvolvimento institucional PDI (2013-2017). Foz do Iguaçu, 2013. Disponível em:

<http://www.unila.edu.br/sites/default/files/files/PDI\%20UNILA\%2020132017.pdf>. Acesso em: 9 out. 2017.

WÜSTER, Eugene. Introducción a la teoría general de la terminología y a la lexicografía terminológica. Barcelona: Institut Universitari de Lingüística Aplicada, 1998. 